\title{
Advanced Compton scattering light source R\&D at LLNL
}

F. Albert, S. G. Anderson, G. Anderson, S. M. Betts, T. S. Chu, D. J. Gibson, R. A. Marsh, M. Messerly, M. Y. Shverdin, S. Wu, F. V. Hartemann, C. W. Siders, C. P. Barty

February 18, 2010

Ultrafast Phenomena Snowmass, CO, United States July 18, 2010 through July 23, 2010 
This document was prepared as an account of work sponsored by an agency of the United States government. Neither the United States government nor Lawrence Livermore National Security, LLC, nor any of their employees makes any warranty, expressed or implied, or assumes any legal liability or responsibility for the accuracy, completeness, or usefulness of any information, apparatus, product, or process disclosed, or represents that its use would not infringe privately owned rights. Reference herein to any specific commercial product, process, or service by trade name, trademark, manufacturer, or otherwise does not necessarily constitute or imply its endorsement, recommendation, or favoring by the United States government or Lawrence Livermore National Security, LLC. The views and opinions of authors expressed herein do not necessarily state or reflect those of the United States government or Lawrence Livermore National Security, LLC, and shall not be used for advertising or product endorsement purposes. 


\title{
Advanced Compton scattering light source R\&D at LLNL
}

\author{
F. Albert, S.G. Anderson, G. Anderson, S.M. Betts, T.S. Chu, D.J. Gibson, R.A. Marsh, M. Messerly, M.Y. \\ Shverdin, S. Wu, F.V. Hartemann, C.W. Siders and C.P.J. Barty \\ Lawrence Livermore National Laboratory \\ 7000 East Avenue, Livermore, $C A$ \\ albert6@llnl.gov
}

\begin{abstract}
We report the design and current status of a monoenergetic laser-based Compton scattering 0.52.5 MeV $\gamma$-ray source. Previous nuclear resonance fluorescence results and future linac and laser developments for the source are presented.
\end{abstract}

\section{Introduction}

At $\mathrm{MeV}$ photon energies relevant for nuclear processes, Compton scattering light sources are attractive because of their relative compactness and improved brightness above $100 \mathrm{keV}$, compared to typical $4^{\text {th }}$ generation synchrotrons. Recent progress in accelerator physics and laser technology have enabled the development of a new class of tunable Mono-Energetic Gamma-Ray (MEGa-Ray) light sources based on Compton scattering between a high-brightness, relativistic electron beam and a high intensity laser pulse produced via chirped-pulse amplification (CPA). A new precision, tunable gamma-ray source driven by a compact, high-gradient X-band linac is currently under development and construction at LLNL. High-brightness, relativistic electron bunches produced by an X-band linac designed in collaboration with SLAC will interact with a Joule-class, $10 \mathrm{ps}$, diode-pumped CPA laser pulse to generate tunable $\gamma$-rays in the $0.5-2.5 \mathrm{MeV}$ photon energy range via Compton scattering. Based on the success of the previous Thomson-Radiated Extreme X-rays (T-REX) Compton scattering source at LLNL[1], the source will be used to excite nuclear resonance fluorescence lines in various isotopes; applications include homeland security, stockpile science and surveillance, nuclear fuel assay, and waste imaging and assay. After a brief presentation of successful nuclear resonance fluorescence (NRF) experiments done with T-REX, the new source design, key parameters, and current status are presented.

\section{NRF Experiments}

T-REX experiments have been already performed on an enhanced version of the $100 \mathrm{MeV}$ LLNL electron linac used for previous Compton scattering sources [2]. The electron bunch is accelerated to $\sim 120 \mathrm{MeV}$ and focused with a series of quadrupole magnets. The Interaction Laser System (ILS), that produces the photon beam to collide with the electrons, can deliver $750 \mathrm{~mJ}$ of energy in $25 \mathrm{ps}$ and $0.2 \mathrm{~nm}$ bandwidth at $10 \mathrm{~Hz}$ and $1064 \mathrm{~nm}$. The beam after the compressor can then be frequency doubled or tripled using large aperture DKDP crystals. The ILS is focused into a vacuum chamber, at $180^{\circ}$ with respect to the electron beam, by a $2.4 \mathrm{~m}$ focal length $\mathrm{f} / 50$ lens.

A complete spectral and spatial characterization of this Compton scattering light source has been made: it produces photons with energies between $0.1 \mathrm{MeV}$ and $0.8 \mathrm{MeV}$. The T-REX source is described by its key parameters: size $\left(0.01 \mathrm{~mm}^{2}\right)$, divergence $\left(10 \times 6 \mathrm{mrad}^{2}\right)$, duration $(\mathrm{ps})$, spectrum $\left(15 \%\right.$ bandwidth) and intensity $\left(10^{5}\right.$ photons/shot), all of which are summarized by an on-axis peak brightness of $2.5 \times 10^{15}$ photons $/ \mathrm{mm}^{2} / \mathrm{mrad}^{2} / \mathrm{s} / 0.1 \%$ bandwidth at $0.478 \mathrm{MeV}$. NRF measurements, a promising method for isotopic imaging, assay, and detection, were performed on ${ }^{7} \mathrm{Li}$ using this source [1].

\section{New source design}

\subsection{X-Band linac}

The high brightness electron linac is a key component of the future facility. Design criteria include rf phase and amplitude stability, high-gradient operation at $120 \mathrm{~Hz}$, and low emittance at the interaction point. The emittancecompensated gun design used for this linac is very similar to the $\mathrm{X}$-band $\mathrm{rf}$ gun developed by Vlieks and collaborators [3], with improved field balance and mode separation; it will generate $7 \mathrm{MeV}$ photoelectron bunches with $0.4 \mathrm{nC}$ charge and approximately $1 \mathrm{~mm}$.mrad normalized emittance after compensation in a solenoid field of 7 $\mathrm{kG}$ and a drift of $0.75 \mathrm{~m}$. To generate the electrons at the injector photocathode, a $263 \mathrm{~nm}$ laser pulse, shaped in time and space to have a uniform cylindrical profile, is used. This pulse is generated from an all-fiber front end, which 
provides up to $1 \mathrm{~mJ}, 1053 \mathrm{~nm}$ pulses that are frequency quadrupled, replicated and stacked to generate the desired temporal profile, and clipped to produce the necessary spatial profile. Approximately $400 \mathrm{MW}$ of compressed Xband $\mathrm{rf}$ power will be available to energize the gun and linac. This power will be produced by 2 XL-4 klystrons, each generating $50 \mathrm{MW}, 1.6 \mu$ s pulses at up to $120 \mathrm{~Hz}$ repetition rate; a SLED II cavity will then produce $400 \mathrm{MW}$, $400 \mathrm{~ns}$ pulses. Stability of the $\mathrm{rf}$ is critical, and begins with the HV modulators; to this end solid-state technology combined with high transformer ratios is being considered to drive the klystrons. The SLAC built T53VG3(MC) sections will be used to accelerate the beam up to $250 \mathrm{MV}$; these sections have demonstrated excellent beam dynamics characteristics, as well as high gradient operation $(>65 \mathrm{MV} / \mathrm{m})$. The linac architecture includes a small chicane to mitigate near-axis halo Bremsstrahlung.

\subsection{Interaction laser}

The interaction laser is the other key component of the machine. Stability, robustness, and beam quality are important criteria for the technology choices used in its design. The system uses hyper-dispersion chirped-pulse amplification (HDCPA), pointing and stabilization feedback loops, a fiber front-end, and interferometrically stabilized beam transport to the interaction region. A $10 \mathrm{~J}, 120 \mathrm{~Hz}$ Injection Laser System (10HILS) has been designed to enable photon interaction with nearly all electrons in the accelerator beamline. The 10HILS provides over $120 \mathrm{x}$ the average power of the original T-REX interaction laser system. The 10HILS is based upon diodepumped solid-state laser expertise and technology developed on the Mercury laser project and the Tailored Aperture Ceramic Laser (TACL) at LLNL. Diode pumping is utilized to decrease the thermal load on amplifier slabs, while increasing efficiency and system reliability. The master oscillator - power amplifier architecture starts with a $30 \mu \mathrm{J}$ stretched pulse from the front end laser system, which is pre-amplified to the $100 \mathrm{~mJ}$ level, then image relayed to the four-pass Nd:YAG power amplifier. The 10HILS power amplifier is a layered Nd:YAG/sapphire composite, which allows aggressive thermal management and parasitic suppression in a single compact slab.

\section{Expected gamma-ray performance}

Different benchmarked codes (with T-REX) have been used to predict the gamma-ray output of the new source. In this case, the dose is expected to be $N_{x} \approx 10^{8}$; the electron bunch duration $2 \mathrm{ps}$, the electron beam energy $250 \mathrm{MeV}$, and its normalized emittance $1 \mathrm{~mm} . \mathrm{mrad}$. This translates into a peak brightness of order $10^{22}$ photons $/\left(\mathrm{s} \mathrm{x} \mathrm{mm}^{2} \mathrm{x}\right.$ $\operatorname{mrad}^{2} \times 0.1 \% \mathrm{bw}$ ). More accurate estimates yield projected brightness numbers ranging between $10^{21}$ and $10^{22}$, in the same units. These models use the Compton formula, which includes recoil, and the Lorentz-boosted Klein-Nishina differential scattering cross-section; they also provide estimates of the source linewidth, which is bounded by the laser spectrum and relative energy spread of the electron beam, on the high-frequency side, and by the electron beam emittance in the low-energy tail due to electrons crossing the focus at off-axis angles. Non linear spectral broadening effects have also been studied for the design. This very narrow bandwidth will enable the detailed NRF applications outlined in the introduction.

This work performed under the auspices of the U.S. Department of Energy by Lawrence Livermore National Laboratory under Contract DE-AC52-07NA27344.

\section{References}

[1] F. Albert, S.G. Anderson, G.A. Anderson, S.M. Betts, D.J. Gibson, C.A. Hagmann, J. Hall, M.S. Johnson, M.J. Messerly, V.A. Semenov, M.Y. Shverdin, A.M. Tremaine, F.V. Hartemann, C.W. Siders, D.P. McNabb and C.P.J. Barty, Opt. Letters, 35, vol. 3 354-357 (2010).

[2] F.V. Hartemann, A.M. Tremaine, S.G. Anderson, C.P.J. Barty, S.M. Betts, R. Booth, W.J. Brown, J.K. Crane, R.R. Cross, D.J. Gibson, D.N. Fittinghoff, J. Kuba, G.P. Lesage, D.R. Slaughter, A.J. Wooton, E.P. Hartouni, P.T. Springer, J.B. Rosenzweig and A.K. Kerman, Laser and part. Beams, 22, 221-244 (2004).

[3] A.E. Vlieks et al., High Energy Density \& High Power RF: 6th Workshop, 358 (2003). 